\title{
The Effects of HIP, Solution Heat Treatment and Aging Treatments on the Microstructure and Mechanical Properties of Sintering Cobalt-Based Alloys Strengthened with Tantalum Carbide Additives
}

\author{
Shih-Hsien Chang* and Chien-Chung Chen \\ Department of Materials and Mineral Resources Engineering, National Taipei University of Technology, \\ Taipei 10608, Taiwan, R. O. China
}

\begin{abstract}
This study explored a series of HIP processes, solution heat treatments and aging treatments, in which various amounts of tantalum carbide $(\mathrm{TaC})$ powder are added for sintering cobalt-based composite materials. Experimental results showed that the highest transverse rupture strength (TRS) of $1812.4 \mathrm{MPa}$ was obtained by the 10 mass $\% \mathrm{TaC}$ added to cobalt-based alloys, which was sintered at $1270^{\circ} \mathrm{C}$, and followed by HIP processes, solution heat treatments, and aging treatments for $12 \mathrm{~h}$. The hardness increased to $80.1 \mathrm{HRA}$. In addition, the added amounts of TaC powder and aging times played important roles in improving the mechanical properties of the cobalt-based alloys. By microstructural observations, it was found that both $\mathrm{M}_{6} \mathrm{C}$ and $\mathrm{M}_{23} \mathrm{C}_{6}$ carbides precipitated in the matrix of the $0 \% \mathrm{TaC}$ specimens after various aging treatments. However, the more refined and uniform precipitations of $\mathrm{M}_{6} \mathrm{C}, \mathrm{M}_{23} \mathrm{C}_{6}$ and $\mathrm{MC}$ carbides were precipitated in the matrix of the TaC powders added to cobalt-based alloys after $12 \mathrm{~h}$ of aging treatment at $850^{\circ} \mathrm{C}$. This result was effective in improving the mechanical properties of the cobalt-based alloys. Conversely, $15 \mathrm{~h}$ of aging treatment at $850^{\circ} \mathrm{C}$ generated an over-aging phenomenon, which resulted in a decrease in TRS value. [doi:10.2320/matertrans.M2014066]
\end{abstract}

(Received February 21, 2014; Accepted July 28, 2014; Published October 25, 2014)

Keywords: hot isostatic pressing (HIP), aging, tantalum carbide (TaC), cobalt-based alloy, $M_{6} C_{,} M_{23} C_{6}$

\section{Introduction}

Generally, superalloys are widely used under different application conditions. For example, cobalt-based alloys have good wear resistance, corrosion resistance at high temperature and excellent heat fatigue resistance. Those are exactly consistent with the requirements of critical or supercritical high temperature steam valves that demand higher wear resistance and corrosion resistance. Many of the properties of these alloys arise from the crystallographic nature of cobalt, the solid-solution strengthening effects of chromium, tungsten, and molybdenum of the metal carbides. ${ }^{1-3)}$ Tantalum carbide $(\mathrm{TaC})$ is a very important and promising material due to its unique combination of properties, ${ }^{4)}$ such as a melting point in excess of $3800^{\circ} \mathrm{C}$. Unique combination of good chemical stability, good corrosion resistance, high hardness and other good mechanical properties make it potential for rocket nozzles and scramjet component applications. ${ }^{5,6)}$

Metal matrix composites (MMC) are known to be very hard materials and to exhibit exceptional wear resistance. In this respect, several investigators used $\mathrm{TaC}$ as reinforcing medium in a cobalt-based alloy in order to enhance mechanical properties. Furthermore, wear resistance of MMC have been developed, which are produced by powder metallurgy $(\mathrm{P} / \mathrm{M}){ }^{7,8)}$ Conventionally sintered $\mathrm{P} / \mathrm{M}$ parts usually have over $5 \%$ porosity. Enhanced sintering techniques can be applied to obtain higher density and reduced porosity in sintered parts. ${ }^{7-9)}$ Powder metallurgy, such as hot isostatic pressing (HIP) can be used for upgrading casting, packing pre-sintered components and consolidating powders; it involves the simultaneous application of high pressure and elevated temperature in a specially constructed vessel. Besides, HIP is largely concerned with the removal of pores. ${ }^{10-13)}$

*Corresponding author, E-mail: changsh@ntut.edu.tw
Furthermore, the precipitation strengthened cobalt-based alloys contain $\mathrm{Cr}$, Mo and $\mathrm{W}$ elements, which trend to cause precipitation of carbides (such as $\mathrm{MC}, \mathrm{M}_{6} \mathrm{C}$ and $\mathrm{M}_{23} \mathrm{C}_{6}$ ) during appropriate heat treatment., ${ }^{9,14}$ Our previous studies added different amounts of $\mathrm{TaC}$ powders $(0,10,15$ and $20 \operatorname{mass} \%)$ to the cobalt-based alloy powders. The experimental results showed that adding 10 mass $\% \mathrm{TaC}$ powder to cobalt-based alloys and sintering at $1270^{\circ} \mathrm{C}$ for $1 \mathrm{~h}$ was the optimal process. The aim of this work was to explore a series of HIP processes, solution heat treatments, and aging treatments for cobalt-based composite materials, and examine the effects on the microstructure and mechanical properties of $\mathrm{TaC}$ strengthened cobalt-based alloys.

\section{Experimental Procedures}

In our previous work, different amounts of $\mathrm{TaC}$ powders $(0,10,15$ and 20 mass $\%)$ were added to cobalt-based alloy powders. The cobalt-based powder samples, with various $\mathrm{TaC}$ specimens added, were denoted by $0 \% \mathrm{TaC}, 10 \% \mathrm{TaC}$, $15 \% \mathrm{TaC}$ and $20 \% \mathrm{TaC}$. The vacuum sintering temperature was maintained at $1260,1270,1280$ and $1290^{\circ} \mathrm{C}$ for $1 \mathrm{~h}$. The HIP equipment used in this experiment was from Flow Autoclave Pressure Systems, Inc. The equipment used for the solution heat treatment was a commercial Germanic Schmetz vacuum heat treatment furnace. The aging treatments were performed using a vacuum tube furnace. The parameters of the HIP process were $1250^{\circ} \mathrm{C}, 125 \mathrm{MPa}$ and $100 \mathrm{~min}$. After the HIP process, the samples were heated to $1100^{\circ} \mathrm{C}$ for solution heat treatment and maintained for $40 \mathrm{~min}$; then they were quenched and aged at $850^{\circ} \mathrm{C}$ for soaking times of 9,12 and $15 \mathrm{~h}$, respectively.

To evaluate the influences of HIP and various heat treatments on microstructure and mechanical properties of TaC strengthened cobalt-based alloys, this study conducted apparent porosity, hardness, transverse rupture strength 
(TRS) tests, optical microscope (OM, Nikon Eclipse Lv150) and scanning electron microscopy (SEM, Hitachi-S4700) microstructure inspections. The Hung Ta universal material test machine (HT-9501A) with a maximum load of $245 \mathrm{kN}$ was used for 3-point bending (TRS) tests (ASTM B528-05). $R_{\mathrm{bm}}$ was the transverse rupture strength, which determined as the fracture stress in the surface zone. $F$ was maximum fracture load, $L$ was $30 \mathrm{~mm}, k$ was chamfer correction factor (normally 1.00-1.02), $b$ and $\mathrm{h}$ were $5 \mathrm{~mm}$ in the equation $R_{\mathrm{bm}}=3 F L k / 2 b h^{2}$, respectively. The specimen dimensions of the 3-point bending test were $5 \mathrm{~mm} \times 5 \mathrm{~mm} \times 40 \mathrm{~mm}$. Porosity test was conducted in accordance to the ASTM C373-88 standard. Hardness tests were measured by Rockwell A hardness (HRA, Indentec 8150LK) with a loading of $588 \mathrm{~N}$, which followed the ASTM B294 standard.

\section{Results and Discussion}

In this experiment, the mean particle size of $\mathrm{TaC}$ powders was $1.45 \pm 0.5 \mu \mathrm{m}$, and the density was $13.9 \mathrm{~g} \mathrm{~cm}^{-3}$. The mean particle size of cobalt-based powder was $8 \pm 1 \mu \mathrm{m}$, and the chemical composition (mass \%) is as follows: $29-33 \% \mathrm{Cr}$, 8-10\% W, $\leqq 3.0 \% \mathrm{Fe}, 1.5-3.0 \% \mathrm{Ni}, 1.4-1.7 \% \mathrm{C}, 1-1.5 \% \mathrm{Si}$, $\leqq 1.0 \% \mathrm{Mo}, \leqq 0.5 \% \mathrm{Mn}$. The balance was Co.

All cobalt-based composite specimens were sintered at $1270^{\circ} \mathrm{C}$ for $1 \mathrm{~h}$. Figure 1 shows the porosity of the different composite specimens after as-sintered, HIPed, HIP plus and different aging treatments. Our previous study $^{8)}$ found that the liquid-phase sintering (LPS) effect was observed in decreasing porosity. Figure 1 shows that the porosity of the $0 \% \mathrm{TaC}$ specimens decreased to $2.2 \%$, and the 10,15 and $20 \% \mathrm{TaC}$ specimens decreased to less than $2 \%$ after the optimal sintering temperature $\left(1270^{\circ} \mathrm{C}\right)$. Furthermore, the porosity of $0 \% \mathrm{TaC}$ sintered specimens had a slight decrease $(2.2 \% \rightarrow 1.8 \%)$ after HIP process. According to the literature, ${ }^{15}$ ) the closed pores can be effectively eliminated by the HIP process. When the specimen was under a uniform pressure, there was a reduction in internal closed pores, and the microstructure and mechanical properties showed a very substantial improvement. However, the sintered specimen itself provided good densification after $1270^{\circ} \mathrm{C}$ sintering. Thus, a small improvement in the porosity level was displayed.

In addition, the porosities of 10,15 and $20 \% \mathrm{TaC}$ specimens only experienced a slight decrease after the HIP process. When the sintered specimen was compressed, the internal closed pores were effectively eliminated after the HIP process; therefore, the sintered density was improved. When the sintered density was low, the improvement efficiency of the HIP treatment was limited. Compared with $0 \% \mathrm{TaC}$ specimens, the 10 mass $\% \mathrm{TaC}$ powder added to the cobalt-based alloys obviously affected the diffusion of particles, which resulted in a slight decrease in the porosity level after the HIP process. However, for the $15 \% \mathrm{TaC}$ specimens, the porosity was not clearly improved after the HIP process; this is because the LPS effect decreased the porosity after the optimal sintering process. Moreover, adding a higher content (15 mass \%) of the TaC powder resulted in an increased concentration of micro pores after the sintering process. There were still many gaps between the $\mathrm{TaC}$ and

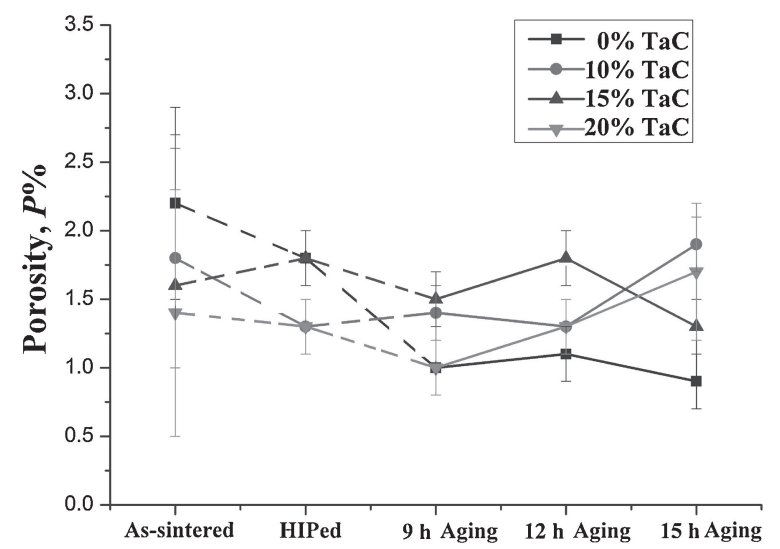

Fig. 1 Comparison of the porosity of different composite specimens by as-sintered, HIPed $\left(1250^{\circ} \mathrm{C}, 125 \mathrm{MPa}\right.$ and $\left.100 \mathrm{~min}\right)$ and different solution heat treatment and aging treatments $(9,12$ and $15 \mathrm{~h})$.

cobalt-based powders that could not be wetted, which caused several internal pores to remain in the specimen. Consequently, these closed pores were not completely and effectively eliminated by the HIP process.

On the other hand, the solution heat treatment and aging treatment contributed to a better strengthening phase of the carbide precipitations for cobalt-based composite materials, as well as the re-distribution of carbide precipitations. Therefore, the porosity level was affected. Figure 1 shows that the porosity of the $0 \% \mathrm{TaC}$ specimens was obviously reduced to below $1.1 \%$ after the solution heat treatment and aging treatment $(9,12$ and $15 \mathrm{~h})$. The results suggested that the porosity decreased through slow diffusion of the particles after a long-time and high-temperature aging treatment $\left(850^{\circ} \mathrm{C}-9,12\right.$ and $\left.15 \mathrm{~h}\right)$. Moreover, 10,15 and $20 \% \mathrm{TaC}$ specimens only showed a slight evolution in porosity after the aging treatment. For example, the porosity of the $20 \% \mathrm{TaC}$ specimens decreased to $1.0 \%$ after $9 \mathrm{~h}$ of aging treatment, but a slight increase of $0.7 \%$ was observed after a longer aging treatment $(15 \mathrm{~h})$. The aging treatments contributed to a redistribution of carbide precipitates, which resulted in a decrease in the porosity level.

Figure 2 shows the hardness and TRS tests of different composite specimens by as-sintered, HIP processes, and heat treatments. The hardness obviously increased as the $\mathrm{TaC}$ added to cobalt-based powders increased after optimal sintering treatment. In addition, the hardness of $0 \% \mathrm{TaC}$ specimens rapidly increased $(70.2 \rightarrow 75.7$ HRA) after the HIP process, as shown in Fig. 2(a). Since HIP can effectively eliminate internal micro pores, when the specimens were subjected to the high compressive stress, the densification of the specimens was significantly improved and the treatment enhanced the hardness. A large number of solute atoms dissolved, and re-dissolved back into the matrix after the solution heat treatment. Meanwhile, the re-dissolved atoms began to generate carbide precipitations through the long aging process. Normally, suitable and longer aging treatment will result in more carbide precipitations which affect the hardness of the material. As a result, the hardness of $0 \% \mathrm{TaC}$ specimens was increased as the aging time increased. The highest hardness of $0 \%$ TaC specimens was 77.3 HRA, which appeared after $15 \mathrm{~h}$ of aging treatment. 

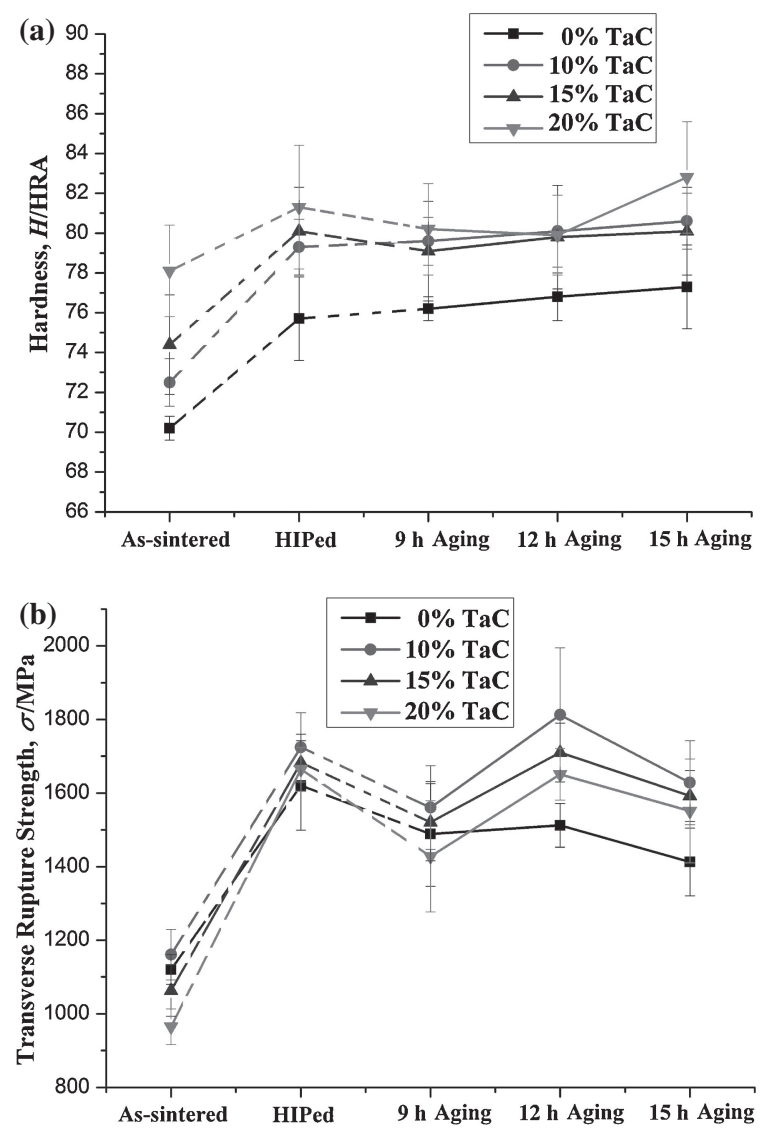

Fig. 2 Comparison of the hardness and TRS tests of different composite specimens by as-sintered, HIPed $\left(1250^{\circ} \mathrm{C}, 125 \mathrm{MPa}\right.$ and $\left.100 \mathrm{~min}\right)$ and solution heat treatment and aging treatments $(9,12$ and $15 \mathrm{~h})$.

In addition, all the hardness of $10 \% \mathrm{TaC}, 15 \% \mathrm{TaC}$ and $20 \% \mathrm{TaC}$ specimens effectively increased after the HIP process, as shown in Fig. 2(a). Compared with the only sintered specimens, the hardness was enhanced about $5 \%$ in $20 \% \mathrm{TiC}$ specimens. In particular, the hardness of $20 \%$ TaC specimens reached 82.3 HRA after the HIP process. However, the hardness of $10 \% \mathrm{TaC}, 15 \% \mathrm{TaC}$ and $20 \% \mathrm{TaC}$ specimens showed a downward trend after $9 \mathrm{~h}$ of aging treatment. This was mainly due to the carbide distributions, which were not stable and uniform, and resulted in poor hardness after a shorter aging treatment $(9 \mathrm{~h})$. By increasing the aging duration, all the hardness of the $10 \% \mathrm{TaC}, 15 \%$ $\mathrm{TaC}$ and $20 \% \mathrm{TaC}$ specimens showed an upward trend because the high temperature environment $\left(850^{\circ} \mathrm{C}\right)$ of the aging treatments was conducive in the strengthening phases to precipitate various carbides. Meanwhile, the carbide precipitations increases and the hardness enhanced under a longer aging time. The results suggested that the HIP process, along with a suitable aging treatment, is advantageous to the hardness of cobalt-based composite specimens.

Figure 2(b) shows that all the TRS values of the $0 \% \mathrm{TaC}$, $10 \% \mathrm{TaC}, 15 \% \mathrm{TaC}$ and $20 \% \mathrm{TaC}$ specimens significantly increased after the HIP process. The TRS of $0 \% \mathrm{TaC}$ specimens increased from $1120.5 \mathrm{MPa}$ (sintered) to 1620.8 $\mathrm{MPa}$ (HIPed), $10 \% \mathrm{TaC}$ increased from $1160.6 \mathrm{MPa}$ to 1724.5 MPa, 15\% TaC increased from 1063.3 MPa to 1682.7 $\mathrm{MPa}$ and $20 \% \mathrm{TaC}$ increased from 964.6 MPa to $1664.2 \mathrm{MPa}$, respectively. The maximum increase per sample was $72.5 \%$ after the HIP process. The HIP process effectively and significantly strengthened cobalt-based composite materials. Moreover, all the TRS values of $0 \%, 10 \% \mathrm{TaC}, 15 \% \mathrm{TaC}$ and $20 \% \mathrm{TaC}$ specimens showed a downward trend after $9 \mathrm{~h}$ of aging treatment. By increasing the aging time to $12 \mathrm{~h}$, the TRS value was obviously increased. It is reasonable to suggest that the distribution of carbide precipitations in the cobalt-based composite specimens was more uniform after $12 \mathrm{~h}$ of aging treatment, which is advantageous to the TRS value. The optimal TRS value $(1812.4 \mathrm{MPa})$ appeared in $10 \% \mathrm{TaC}$ specimens after $1270^{\circ} \mathrm{C}$ of sintering, HIP process, solution heat treatment, and $12 \mathrm{~h}$ of aging treatment. However, the over-aging effects obviously appeared after $15 \mathrm{~h}$ of aging treatment. Because the excessive precipitations of carbides resulted in continuous accumulation, the strength showed a decreasing trend, as seen in Fig. 2(b). According to the above results and discussion, the optimal process and relatively better mechanical properties were obtained through $10 \% \mathrm{TaC}$ specimens sintered at $1270^{\circ} \mathrm{C}$, followed by the HIP process $\left(1250^{\circ} \mathrm{C} 125 \mathrm{MPa} 100 \mathrm{~min}\right)$ and $12 \mathrm{~h}$ of aging treatments at $850^{\circ} \mathrm{C}$.

Figure 3 shows the SEM observation and EDS analysis of $0 \% \mathrm{TaC}$ sintered specimens after the HIP process. The main elements of the grain boundary (Point A) were $\mathrm{Co}, \mathrm{Cr}$ and $\mathrm{W}$, which belong to the W-rich of $\mathrm{M}_{6} \mathrm{C}$ carbide distributions. ${ }^{14)}$ This result indicates that the HIP process did not change the carbide precipitation types of original cobalt-based alloys $(0 \% \mathrm{TaC})$. The strengthened mechanisms of $0 \% \mathrm{TaC}$ specimens, which belong to the $\mathrm{M}_{6} \mathrm{C}$ carbide precipitation types, did not differ after the HIP process. Figure 4 shows the SEM and EDS analysis of $0 \% \mathrm{TaC}$ sintered specimens after the HIP process, the solution heat treatment, and $12 \mathrm{~h}$ of aging treatment at $850^{\circ} \mathrm{C}$. A gray area (Point $\mathrm{A}$ ) of $\mathrm{W}$-rich $\mathrm{M}_{6} \mathrm{C}$ and a black area (Point $\mathrm{B}$ ) of $\mathrm{Cr}$-rich $\mathrm{M}_{23} \mathrm{C}_{6}$ carbide precipitations existed in the matrix and grain boundaries. ${ }^{14)}$ A comparison of Fig. 4 with Fig. 3 shows that the carbide precipitation types of $0 \%$ TaC specimens transformed $\mathrm{M}_{6} \mathrm{C}$ into $\mathrm{M}_{6} \mathrm{C}$ and $\mathrm{M}_{23} \mathrm{C}_{6}$ after the solution heat treatment and aging treatment because the $\mathrm{M}_{6} \mathrm{C}$ carbides re-dissolved back into the matrix after a solution heat treatment, while the aging heat treatment attributed to the growth of $\mathrm{M}_{23} \mathrm{C}_{6}$ carbides. According to the literature, ${ }^{16)}$ the $\mathrm{M}_{23} \mathrm{C}_{6}$ precipitation began from the grain boundary, which has better effect to obstruct the dislocation slip. If the aging time were too long, the cobalt-based alloy was likely to cause coarsening precipitation and become the network structure, which leads to a lower fracture toughness.

In the research, the carbide precipitation types from $10 \%$, $15 \%$ and $20 \% \mathrm{TaC}$ added to cobalt-based alloys were almost all the same. Therefore, this study selected the $10 \% \mathrm{TaC}$ specimens as the representative for further analysis. Figure 5 shows the SEM observation and EDS analysis of the $10 \%$ $\mathrm{TaC}$ sintered specimens after the HIP process. There were three types of carbide distribution (as shown in points A, B and $\mathrm{C}$ ) for the $10 \% \mathrm{TaC}$ specimens after the HIP process. The gray area of Point $\mathrm{A}$ was $\mathrm{W}$-rich $\mathrm{M}_{6} \mathrm{C}$, the black area of Point $\mathrm{B}$ was $\mathrm{Cr}$-rich $\mathrm{M}_{23} \mathrm{C}_{6}$ and a light gray area in Point $\mathrm{C}$ was MC $(\mathrm{M}=\mathrm{Ta})$ carbides, respectively. Furthermore, Fig. 6 shows that the $10 \% \mathrm{TaC}$ specimens also possessed three types of carbide distribution after the HIP process, the 

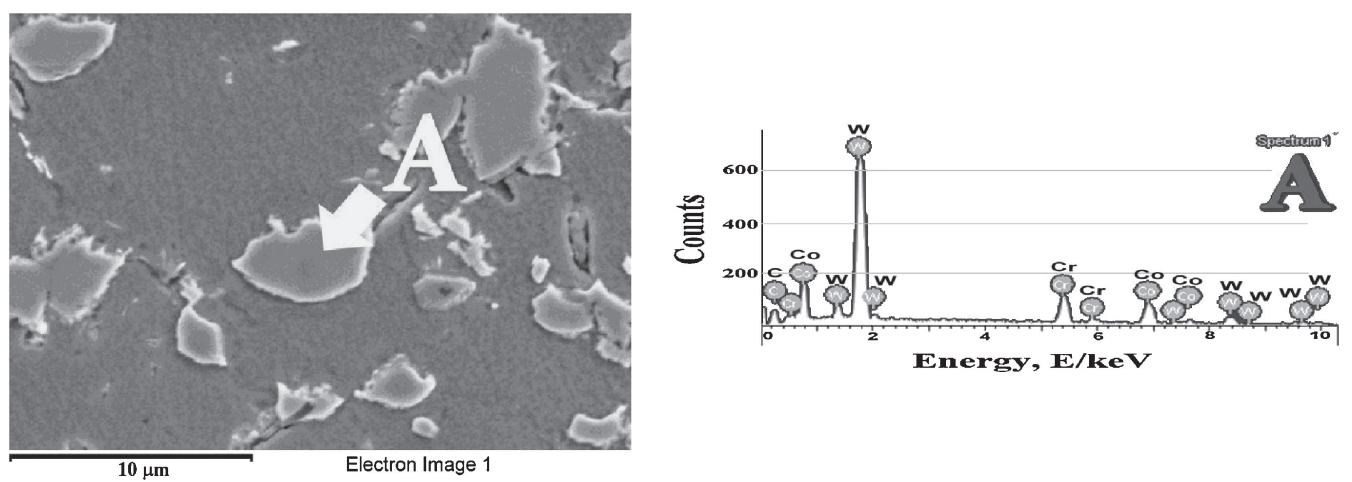

Fig. 3 SEM observation and EDS analysis of the $0 \% \mathrm{TaC}$ specimens by sintering at $1250^{\circ} \mathrm{C}, 125 \mathrm{MPa}$ and $100 \mathrm{~min}$ HIP treatment.
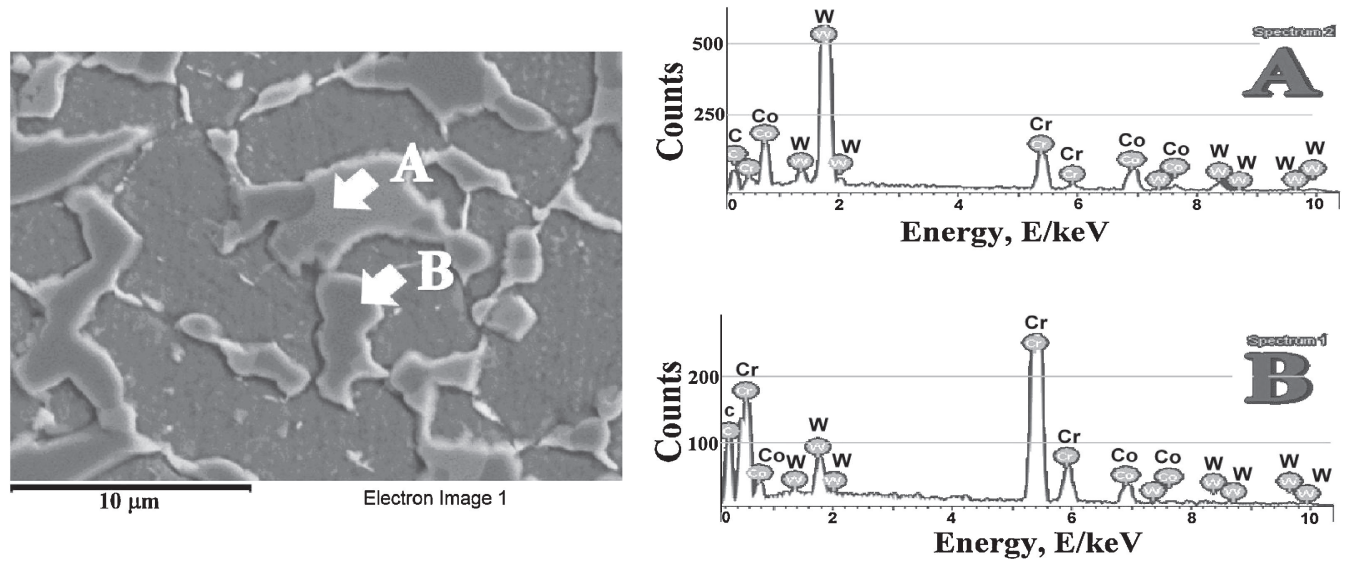

Fig. 4 SEM observation and EDS analysis of the $0 \% \mathrm{TaC}$ specimens by sintering at $1250^{\circ} \mathrm{C}, 125 \mathrm{MPa}$ and $100 \mathrm{~min}$ HIP plus solution heat treatment and $850^{\circ} \mathrm{C} 12 \mathrm{~h}$ aging treatments.
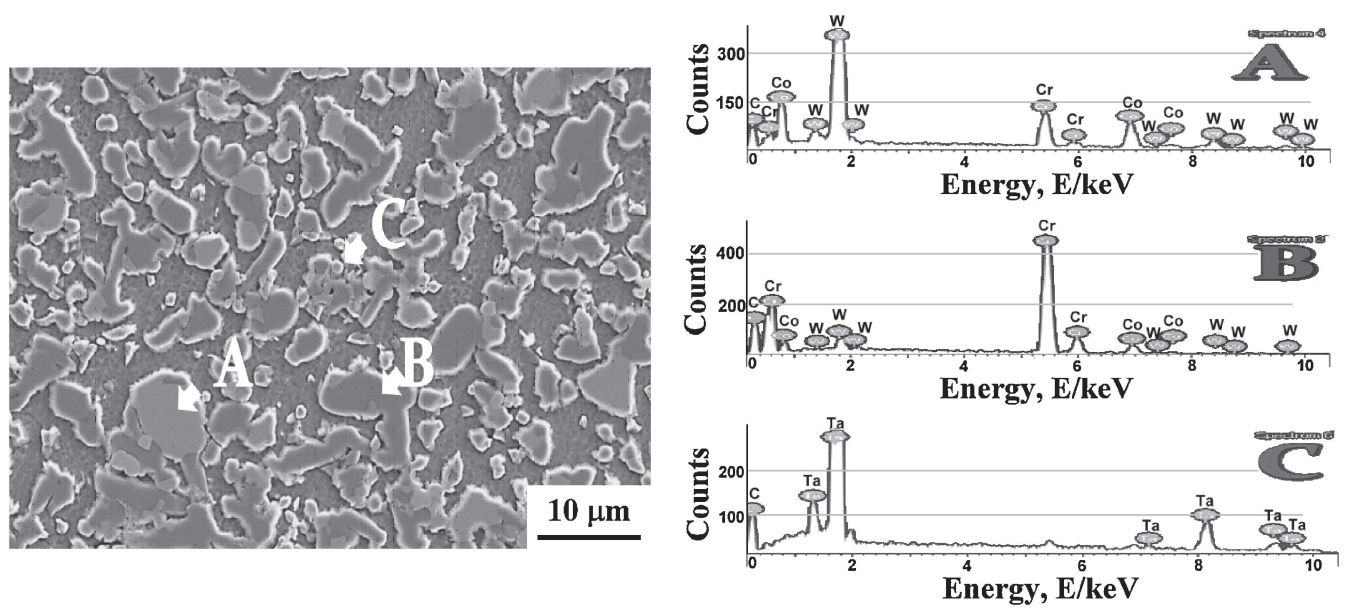

Fig. 5 SEM observation and EDS analysis of the $10 \% \mathrm{TaC}$ specimens by sintering at $1250^{\circ} \mathrm{C}, 125 \mathrm{MPa}$ and $100 \mathrm{~min} \mathrm{HIP}$ treatment.

solution heat treatment, and $12 \mathrm{~h}$ of aging treatments at $850^{\circ} \mathrm{C}$. They were the W-rich $\mathrm{M}_{6} \mathrm{C}$ of Point $\mathrm{A}, \mathrm{Cr}$-rich $\mathrm{M}_{23} \mathrm{C}_{6}$ of Point $\mathrm{B}$ and $\mathrm{MC}$ carbide of Point $\mathrm{C}$, respectively. All carbides precipitated slowly and grew as the aging time increased. A comparison of results with Fig. 5 shows that the re-precipitated carbides were more refined and had uniform distribution after $12 \mathrm{~h}$ of aging treatment (Fig. 6); thus, the TRS value revealed a significant increase (Fig. 2(b)).

Figure 7 shows the BEI observation of the $0 \%$ TaC specimens after sintering, the HIP process, and different heat treatments. Some carbide precipitations $\left(\mathrm{M}_{6} \mathrm{C}\right)$ distributed in the matrix and grain boundaries after sintering and the HIP process, as shown in Figs. 7(a) and 7(b). Moreover, the carbide precipitation types $\left(\mathrm{M}_{6} \mathrm{C}\right)$ obviously transformed into the $\mathrm{M}_{6} \mathrm{C}$ and $\mathrm{M}_{23} \mathrm{C}_{6}$ after $9 \mathrm{~h}$ of aging treatment, as shown in Fig. 7(c). As the aging time increased to $12 \mathrm{~h}$, these carbide precipitations produced more and uniform distribution, and many $\mathrm{M}_{23} \mathrm{C}_{6}$ carbides existed in the grain boundary, as shown in Fig. 7(d). The carbides coarsening phenomenon clearly appeared in the microstructure after $15 \mathrm{~h}$ of aging treatment at $850^{\circ} \mathrm{C}$; meanwhile, the amounts of $\mathrm{M}_{23} \mathrm{C}_{6}$ decreased, and $\mathrm{M}_{6} \mathrm{C}$ increased relatively, as shown in Fig. 7(e), resulting in 

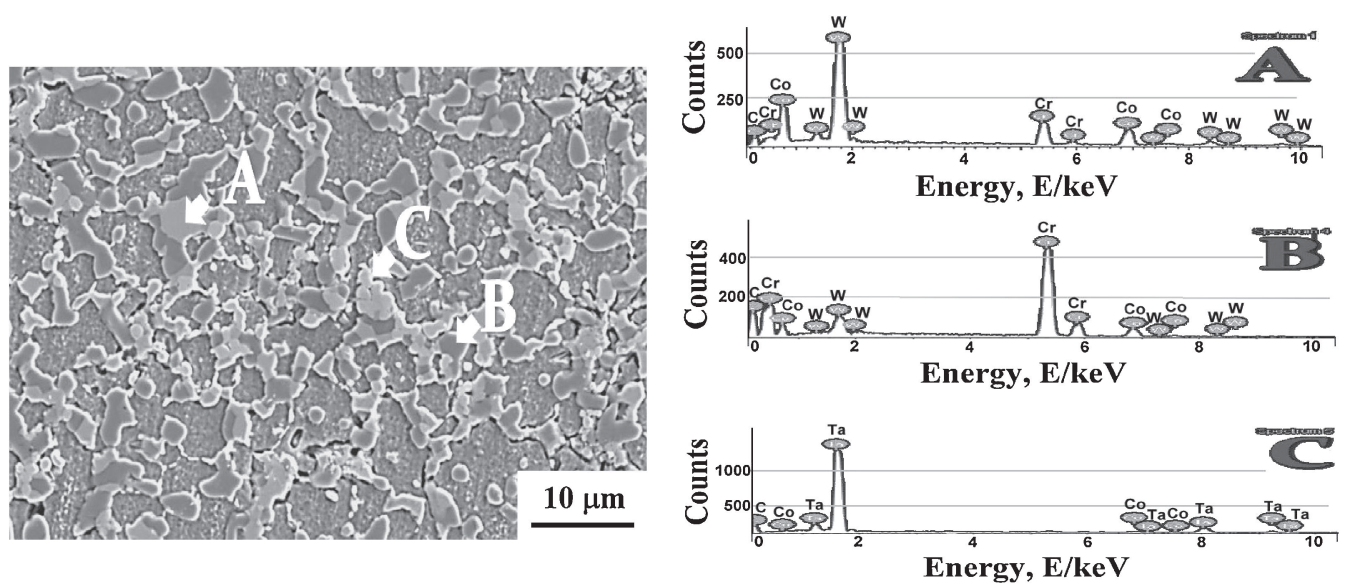

Fig. 6 SEM observation and EDS analysis of the $10 \% \mathrm{TaC}$ specimens by sintering at $1250^{\circ} \mathrm{C}, 125 \mathrm{MPa}$ and 100 min $\mathrm{HIP}$ plus solution heat treatment and $850^{\circ} \mathrm{C} 12 \mathrm{~h}$ aging treatments.
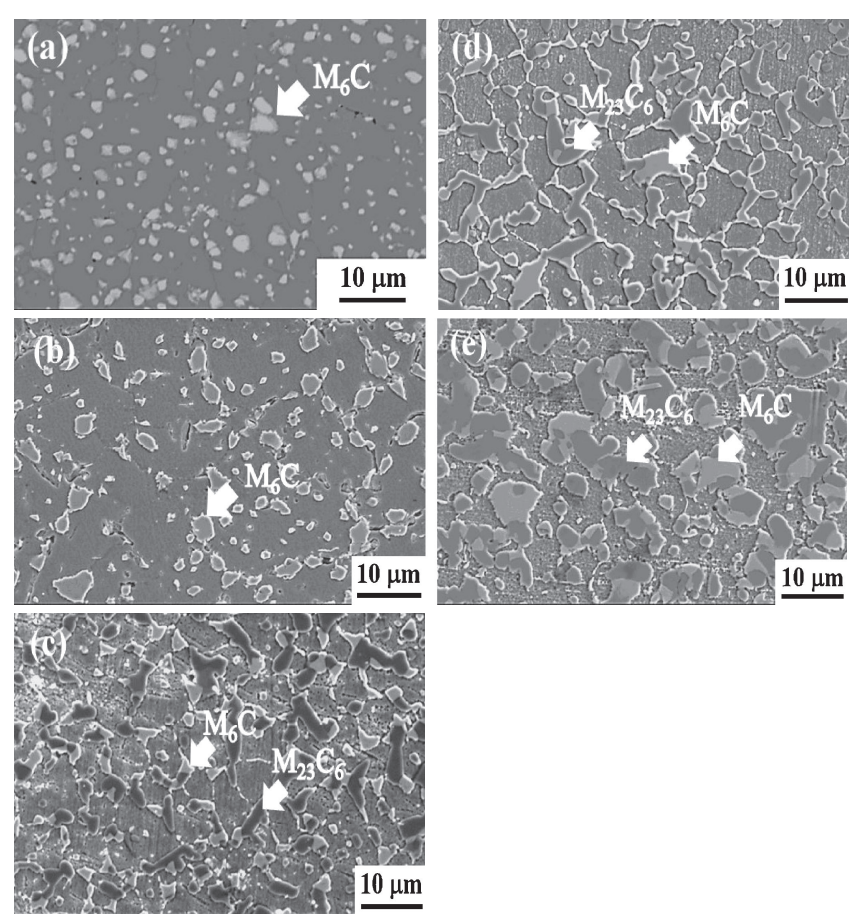

Fig. 7 BEI observation of the $0 \%$ TaC specimens by sintering, HIP and different heat treatments: (a) as-sintered, (b) HIPed, (c) $850^{\circ} \mathrm{C} 9 \mathrm{~h}$ aging, (d) $850^{\circ} \mathrm{C} 12 \mathrm{~h}$ aging, (e) $850^{\circ} \mathrm{C} 15 \mathrm{~h}$ aging.

a lower strength $(1412.5 \mathrm{MPa})$ of cobalt-based composite materials.

Figure 8 shows the BEI observation of $10 \% \mathrm{TaC}$ specimens after sintering, the HIP process, and different heat treatments. There were three types of carbide distribution (MC, $\mathrm{M}_{6} \mathrm{C}$ and $\mathrm{M}_{23} \mathrm{C}_{6}$ ) for $10 \%$ TaC specimens after sintering and the HIP process, as shown in Figs. 8(a) and 8(b). In addition, the initial precipitations of carbides were relatively small and few after $9 \mathrm{~h}$ of aging treatment. There were mainly $\mathrm{M}_{6} \mathrm{C}$ carbides, as shown in Fig. 8(c). As the aging time increased to $12 \mathrm{~h}$, carbide precipitations grew into more refined and uniform distribution, as shown in Fig. 8(d). Meanwhile, there were three kinds of carbide precipitations that clearly appeared. Consequently, the TRS test of $10 \%$ $\mathrm{TaC}$ specimens possessed the highest value (1812.4 MPa)
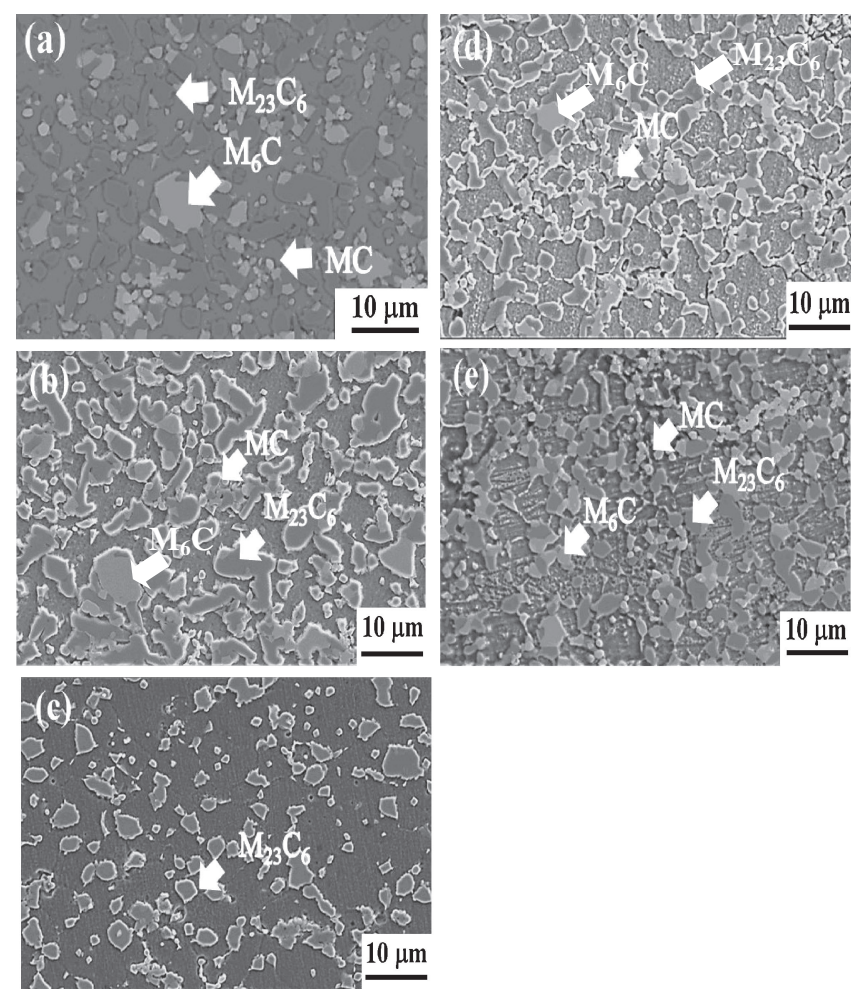

Fig. 8 BEI observation of the $10 \% \mathrm{TaC}$ specimens by sintering, HIP and different heat treatments: (a) as-sintered, (b) HIPed, (c) $850^{\circ} \mathrm{C} 9 \mathrm{~h}$ aging, (d) $850^{\circ} \mathrm{C} 12 \mathrm{~h}$ aging, (e) $850^{\circ} \mathrm{C} 15 \mathrm{~h}$ aging.

after $12 \mathrm{~h}$ of aging treatment. However, an excessive and continuous network of carbide precipitation appeared in the matrix, which resulted in lower strength $(1628.1 \mathrm{MPa})$ after $15 \mathrm{~h}$ of aging treatment, as shown in Fig. 8(e).

The results were further compared in Fig. 2(b). The TRS tended to decrease as the added amount of $\mathrm{TaC}$ increased from 10 to 20 mass $\%$ after various aging treatments. It is predicted that after adding more TaC powders, more $\mathrm{MC}$ carbides $(\mathrm{M}=\mathrm{Ta})$ will be precipitated. A large amount of MC carbide accumulation and continuous precipitating in the grain boundaries affected and decreased the cobalt-based alloys strength during TRS tests. Moreover, adding TaC powder to the cobalt-based alloys was helpful in forming the $\mathrm{M}_{23} \mathrm{C}_{6}$ carbide precipitations, which are more effective in 

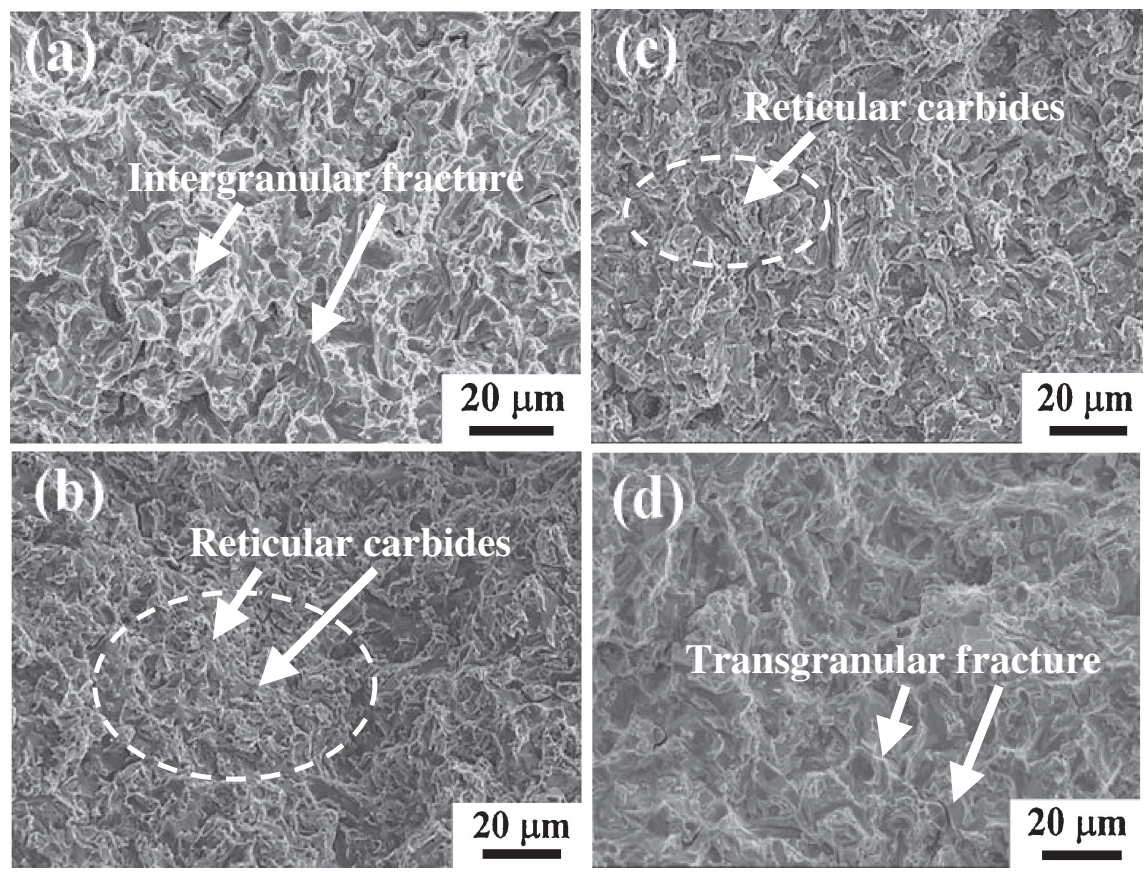

Fig. 9 Fractographs observation of the $0 \% \mathrm{TaC}$ specimens by different process: (a) $1250^{\circ} \mathrm{C}, 125 \mathrm{MPa}$ and $100 \mathrm{~min} \mathrm{HIPed}$, (b) $850^{\circ} \mathrm{C} 9 \mathrm{~h}$ aging, (c) $850^{\circ} \mathrm{C} 12 \mathrm{~h}$ aging, (d) $850^{\circ} \mathrm{C} 15 \mathrm{~h}$ aging.
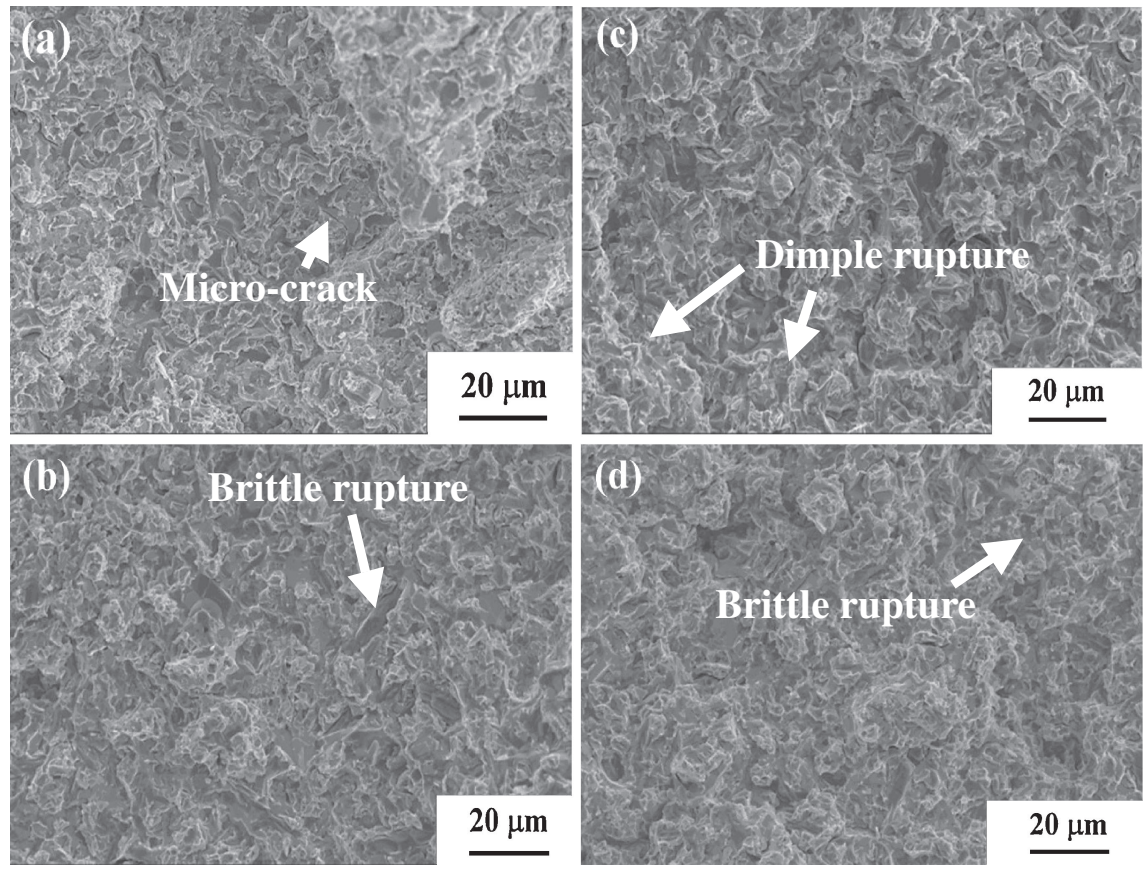

Fig. 10 Fractographs observation of the $10 \% \mathrm{TaC}$ specimens by different process: (a) $1250^{\circ} \mathrm{C}, 125 \mathrm{MPa}$ and $100 \mathrm{~min} \mathrm{HIPed}$, (b) $850^{\circ} \mathrm{C} 9 \mathrm{~h}$ aging, (c) $850^{\circ} \mathrm{C} 12 \mathrm{~h}$ aging, (d) $850^{\circ} \mathrm{C} 15 \mathrm{~h}$ aging.

improving the mechanical properties of cobalt-based alloys. As a result, suitable amounts of $\mathrm{TaC}$ powder play an important role in improving the mechanical properties of a cobalt-based composite material.

Figures 9 and 10 show the fractographs of $0 \% \mathrm{TaC}$ and $10 \% \mathrm{TaC}$ specimens by the HIP process and various heat treatments. The HIP process effectively decreased the internal pores of $0 \% \mathrm{TaC}$ specimens. Figure 9 (a) shows the main fracture morphology is intergranular fracture. As the aging time increased $(9 \mathrm{~h} \rightarrow 12 \mathrm{~h})$, the reticular carbides accelerated to rupture, as shown in Figs. 9(b) and 9(c). Moreover, there was an obvious brittle rupture and transgranular fracture after $15 \mathrm{~h}$ of aging treatment, as shown in Fig. 9(d). This result confirmed that the strength of $0 \% \mathrm{TaC}$ specimens decreased as aging time increased. In addition, $\mathrm{TaC}$ powders added to the cobalt-based alloys effectively prevented the growth of micro-cracks after the HIP process, as show in Fig. 10(a). The aging time was not long enough to cause a sufficient amount of carbide precipitation; the strength of the specimens did not effectively increase after $9 \mathrm{~h}$ of aging treatment. 
Some brittle rupture appeared in Fig. 10(b). Furthermore, Fig. 10(c) shows that the relatively fine and small carbide precipitations led to a dimple rupture after the HIP process and $12 \mathrm{~h}$ of aging treatment, which is advantageous to the TRS value (1812.4 MPa). Figure 10(d) shows that both the continuous network of carbide precipitations and the over aging phenomenon caused some of the block ruptures, which are detrimental to the TRS value.

\section{Conclusions}

The internal pores and micro-cracks of the cobalt-based composite material were effectively reduced after the HIP process. In this study, the porosity level of $10 \% \mathrm{TaC}$ specimens decreased after the HIP process $(1.8 \% \rightarrow 1.3 \%)$. Meanwhile, the TRS value of $10 \% \mathrm{TaC}$ sintered specimens (1120.6 MPa) increased to $1724.5 \mathrm{MPa}$ after the HIP process. In addition, the various carbide precipitations re-dissolved back to the matrix and re-precipitate after the solution heat treatment and aging treatment. The $0 \%$ TaC specimens possessed two different types of carbides after the solution heat treatment and the aging treatment at $850^{\circ} \mathrm{C}$. They were $\mathrm{M}_{6} \mathrm{C}$ and $\mathrm{M}_{23} \mathrm{C}_{6}$ carbides. However, $10 \%$ TaC specimens contained three type of carbides $\left(\mathrm{MC}, \mathrm{M}_{6} \mathrm{C}\right.$ and $\left.\mathrm{M}_{23} \mathrm{C}_{6}\right)$ after the solution heat treatment and aging treatment.

The hardness and TRS value of $10 \% \mathrm{TaC}$ specimens can increase to $80.1 \mathrm{HRA}$ and $1812.4 \mathrm{MPa}$ after HIP, solution heat treatment and $12 \mathrm{~h}$ of aging treatments. Compared with the $0 \% \mathrm{TaC}$ sintered specimen, the hardness enhances $14.1 \%$ $(70.2 \rightarrow 80.1$ HRA) and TRS increases $61.7 \%(1120.5 \rightarrow$ 1812.4 MPa). Significantly, HIP plus solution heat treatment and aging treatment can be effective in improving and enhancing the mechanical properties of cobalt-based alloys with tantalum carbide additives.

\section{Acknowledgments}

This research is supported by the ASSAB STEELS TAIWAN CO., LTD. The authors would like to express their appreciations for Dr. Harvard Chen.

\section{REFERENCES}

1) C. D. Opris, R. Liu, M. X. Yao and X. J. Wu: Mater. Des. 28 (2007) 581-591.

2) S. Hi, A. Xu, J. Fan and H. Wei: Nucl. Eng. Des. 245 (2012) 8-12.

3) M. Sebastiani, V. Mangione, D. De Felicis, E. Bemporad and F. Carassiti: Wear 290-291 (2012) 10-17.

4) J. Ma, Y. Du, M. Wu and M. C. Pan: Mater. Lett. 61 (2007) 3658-3661.

5) L. Liu, F. Ye and Y. Zhou: Mater. Sci. Eng. A 528 (2011) 4710-4714.

6) M. Ali, M. Ürgen and M. A. Atta: Surf. Coat. Technol. 206 (2012) 2833-2838.

7) T. P. Tang and S. H. Chang: ISIJ Int. 48 (2008) 1473-1477.

8) S. H. Chang, S. H. Chen, K. T. Huang and C. Liang: Powder Metall. 56 (2013) 77-82.

9) S. H. Chang and C. C. Ko: Mater. Trans. 54 (2013) 399-404.

10) M. Koizumi: Hot Isostatic Pressing Theory and Applications, International Conference on Hot Isostatic Pressing, (Elsevier Applied Science, 1992) pp. 135-187.

11) T. Garvare: Proceedings of the International Conference on Hot Isostatic Pressing, Lulea/15-17 June, (The Swedish Institute of Production Engineering Research, 1987) pp. 41-152.

12) S. H. Chang, S. H. Chen and K. T. Huang: Mater. Trans. 53 (2012) 1689-1694.

13) S. H. Chang, J. C. Chen, K. T. Huang and J. K. Chen: Mater. Trans. 54 (2013) 1034-1039.

14) S. H. Chang and C. C. Ko: Mater. Trans. 54 (2013) 2049-2054.

15) R. Ahmed, H. L. de. V. Lovelock, S. Davies and N. H. Faisal: Tribol. Int. 57 (2013) 8-21.

16) W. F. Smith: Structure and Properties of Engineering Alloys, 2nd ed., (McGraw-Hill, New York, 1993) pp. 515-528. 